\title{
Lightning Strikes
}

Jeff Renner

Seattle, WA: The Mountaineers Books, 2002

US $\$ 12.95,155$ pages, softcover

This book contains much information about weather-related hazards that is instructive to hikers, mountain bikers, campers, and other outdoor enthusiasts. The information will help one reduce the risks associated with lightning strikes, high winds, floods, wildfires, and other dangerous conditions.

The author's style, anecdotes, analogies, and drawings make it easy for those with no professional or technical training in meteorology or medicine to understand the content. The text consists of anecdotal case reports of individuals caught in dangerous situations, along with meteorological explanations of turbulent weather conditions and safety recommendations. The author provides drawings that are especially helpful in explaining the development and electrification of clouds.

This book was not written as a professional textbook, so it is understandable that there is not a large list of references. However, a few additional references would be helpful. For example, the author lists lightning injuries and complications with percentages (page 22), but the source of this information is not identified. If there is a next edition, I would specifically recommend that the author include reference to a recent comprehensive article on lightning safety and first aid recommendations approved by the Lightning Safety Group in 1998. ${ }^{1}$ There is a hierarchy of lightning safety measures. With proactive planning, such as seeking safe shelter before the storm arrives, an individual may not need to adopt last-resort measures, such as taking the "crouched" position during a lightning storm.

The subtitle of Lightning Strikes is Staying Safe Under Stormy Skies. The author succeeds in bringing this message to the reader by using the format of the four A's (anticipate, access, act, and aid) for those dangerous weather situations (lightning, floods, winds, fire) that might threaten the outdoor athlete. These sections are well written and highly informative. Neophyte and part-time hikers, campers, and bikers would do well to learn many of these messages so that they will be better prepared when sudden, unexpected perils intrude on their outdoor activity. The veteran hiker, camper, and biker could also benefit by reviewing these important lessons.

Michael Cherington, MD

Lightning Data Center, St. Anthony Hospital

Denver, CO, USA

\section{Reference}

1. Zimmerman C, Cooper MA, Holle RL. Lightning safety guidelines. Ann Emerg Med. 2002;39:660-664. 